\title{
Dormancy—The Black Box
}

\author{
Schuyler D. Seeley \\ Plants, Soils, and Biometeorology Department, Utah State University, Logan, UT 84322-4820
}

This workshop was organized to review what we know and don't know about dormancy and to preview current and future molecular and biotechnological approaches that will facilitate endodormancy research and that may eventually open the black box to reveal the basic dormancy mechanism.

Endodormancy has been the subject of many physiological studies; yet, we do not know the basic biochemistry or biophysics of endodormancy induction, transition, or completion. We know more about endodormancy phenology. While the mechanisms of endodormancy induction, transition, and completion are the workings within the black box, phenology only tells us about external characteristics of the box and how various external inputs affect the internal innate mechanism as expressed by changes on the surface.

We know that the endodormancy locus is in meristematic tissues. The endodormancy transition is driven by low temperatures and negated by high temperatures. At least part of the mechanism is biochemical, since scion dormancy can be induced by a dormant stock (Chandler, 1957). Additionally, the nature of the chilling response is genetically controlled (Dennis, 1987). The basic dormancy mechanism, however, has remained elusive, and the paucity of research evidence has allowed significantly different speculative theories to evolve. Disagreements about descriptive terminology are symptomatic of our knowledge. Once the controlling processes are known, the appropriate terminology may become self-evident.

Endodormancy induction in mature trees begins in middle to late summer. It can be monitored by the effect of shoot decapitation on regrowth of subapical lateral buds - the regeneration and growth of the physiological tip (Seeley and Powell, 1981). During induction, endodormancy intensity can be determined in peach [Prunus persica (L.) Batsch.] vegetative buds by the concentration of growth promoter required to force growth (Hatch and Walker, 1969) and in dogwood (Cornus stolonifera Michx.) by the days required for forcing (Fuchigami et al., 1982).

The fact that low temperatures are necessary for the dormancy transition has been known for centuries. The first model, chilling-hour accumulation below 7C, was proposed by Hutchins (Weinberger, 1950). The first temperature-response curve for the dormancy transition mechanism was reported by Hansel (1953) in relation to vernalization. Recently, research on temperature effects on endodormancy of peach, dogwood, and apple (Malus domestica Borkh.) has resulted in more descriptive models for completing the processes in these species (Couvillon and Erez, 1985a; del Real Laborde, 1989; Fishman

The cost of publishing this paper was defrayed in part by the payment of page charges. Under postal regulations, this paper therefore must be hereby marked advertisement solely to indicate this fact. et al., 1987; Fuchigami et al., 1982; Richardson et al., 1974). The efficacy of various temperatures in satisfying or negating the chilling requirement at different times during endodormancy has been worked out for apple seeds (del Real Laborde, 1989) and lateral vegetative peach buds (Couvillon and Erez, 1985a; Erez and Couvillon, 1987).

Models of endodormancy release leading to budburst have recently been formulated (Couvillon and Erez, 1985b; Hanninen, 1990). All of these findings are phenological: while they may describe the surface of the black box, they give few clues as to the basic mechanisms involved. New, exciting research techniques continually arise. Some hold promise for significant progress in dormancy research in the future.

\section{Literature Cited}

Chandler, W.H. 1957. Deciduous orchards. Lea and Febiger, Philadelphia. Couvillon, G.A. and A. Erez. 1985a. Effect of level and duration of high temperatures on rest in the peach. J. Amer. Soc. Hort. Sci. 110:579-581.

Couvillon, G.A. and A. Erez. 1985b. Influence of prolonged exposure to chilling temperatures on budbreak and heat requirement for bloom of several fruit species. J. Amer. Soc. Hort. Sci. 110:47-50.

del Real Laborde, J.I. 1989. An apple rest model for mild winter conditions. PhD Diss., Utah State Univ., Logan.

Dennis, Jr., F.G. 1987. Two methods of studying rest: Temperature alternation and genetic analysis. HortScience 22:820-824.

Erez, A. and G.A. Couvillon. 1987. Characterization of the influence of moderate temperatures on rest completion in peach. J. Amer. Soc. Hort. Sci. 112:677-680.

Fishman, S., A. Erez, and G.A. Couvillon. 1987. The temperature dependence of dormancy breaking in plants: Computer simulation of processes studied under controlled temperatures. J. Theoretical Biol. 126:309-321.

Fuchigami, L.H., C.J. Weiser, K. Kobayashi, R. Timmis, and L.V. Gusta. 1982. A degree growth stage $\left({ }^{\circ} \mathrm{GS}\right)$ model and cold acclimation in temperate woody plants, p. 93-116. In: P.H. Li and A. Sakai (eds.). Plant cold hardiness and freezing stress. Academic, New York.

Hanninen, H. 1990. Modelling bud dormancy release in trees from cool and temperate regions. Acta Forestalia Fennica 213.

Hansel, H. 1953. Vernalisation of winter rye by negative temperatures and the influence of vernalisation upon the lamina length of the first and second leaf in winter rye, spring barley, and winter barley. Ann. Bot. 17:417-432.

Hatch, A.H. and D.R. Walker. 1969. Rest intensity of dormant peach and apricot leaf buds as influenced by temperature, cold hardiness and respiration. J. Amer. Soc. Hort. Sci. 94:304-307.

Richardson, E.A., S.D. Seeley, and D.R. Walker. 1974. A model for estimating the completion of rest for 'Redhaven' and 'Elberta' peach trees. HortScience 9:331-332.

Seeley, S.D. and L.E. Powell. 1981. Seasonal changes of free and hydrolyzable abscisic acid in vegetative apple buds. J. Amer. Soc. Hort. Sci. 106:405-409.

Weinberger, J.H. 1950. Chilling requirements of peach varieties. Proc. Amer. Soc. Hort. Sci. 56:122-128. 